\section{ لِّ}

محمد على كافى (دانشيار)

بيام طريقى * (دانشجوى كارشناسى ارشد) (دانيار)

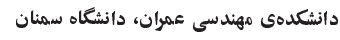

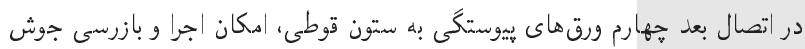

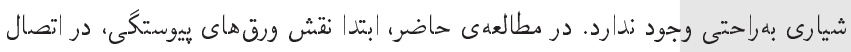

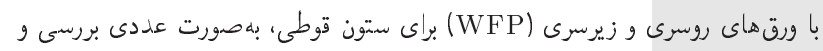

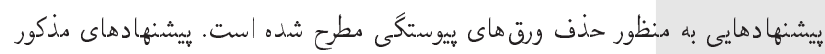

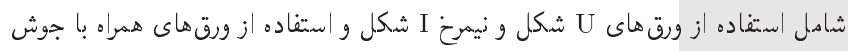

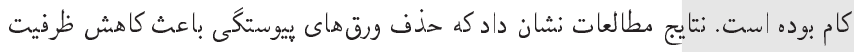

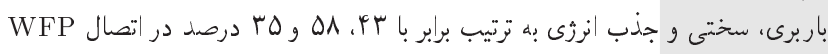

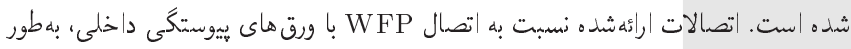

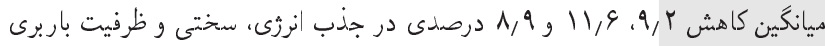

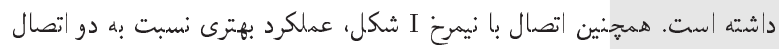
مطرحشدمى ديكر داشته است.

وازكان كليدى: ورقهاى بيوستخى، اتصال با ورق روسرى و زيرسرى، نيمرخ I

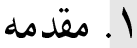

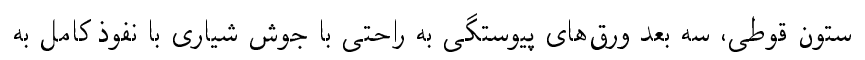

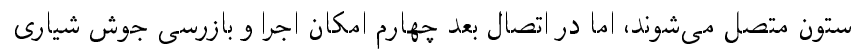

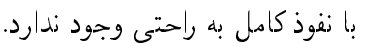

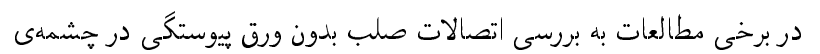

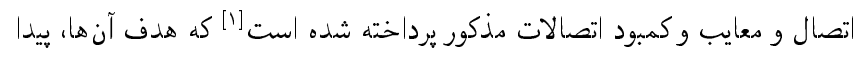

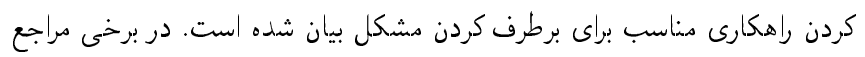

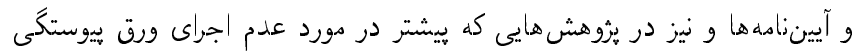

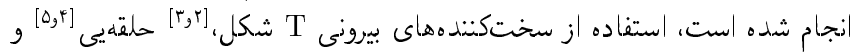

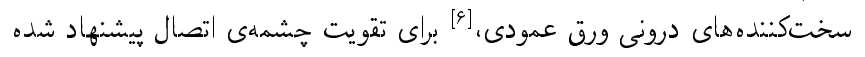

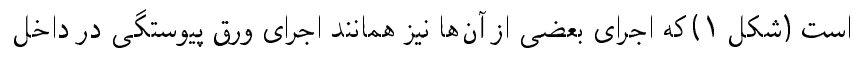

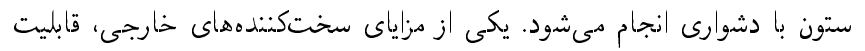

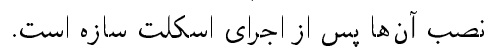

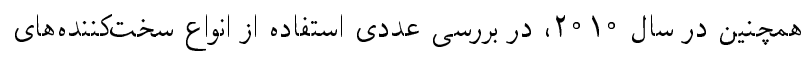

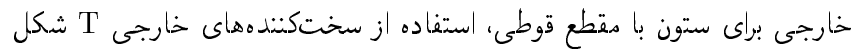

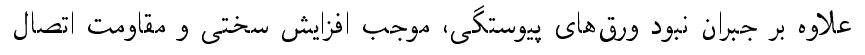

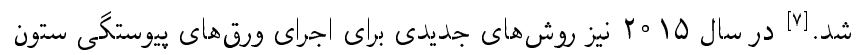

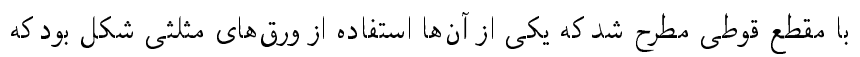

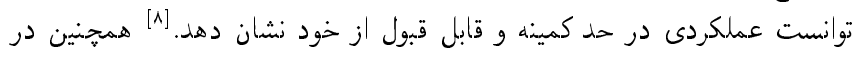

قابهاى خشىى فولادى بايد علاوه بر تأمين دقاومت در برابر بارهاى ثقلى بتواند

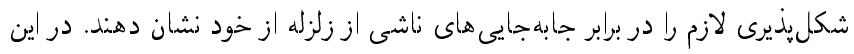

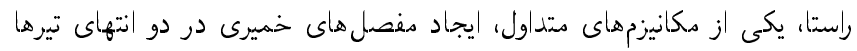

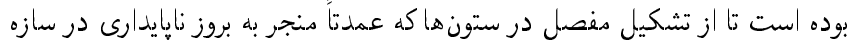
مى شود، جلوكيرى به عمل آيد.

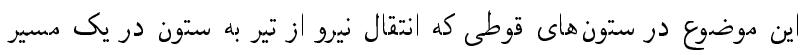

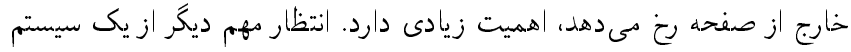

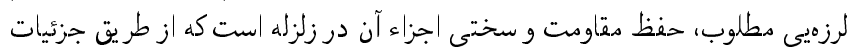

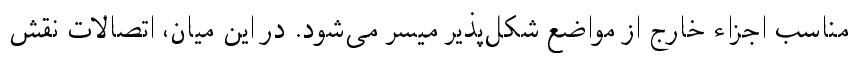

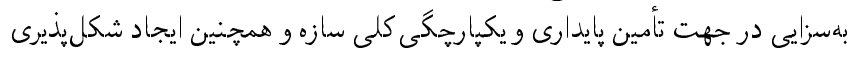

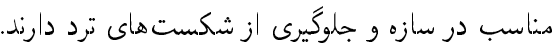

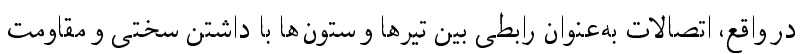

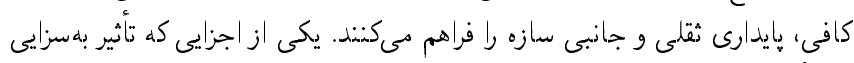

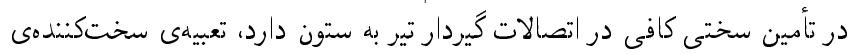

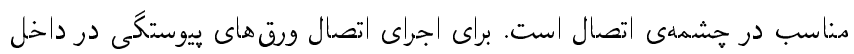

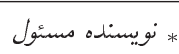

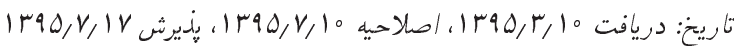
DOI:10.24200/J30.2018.1351 


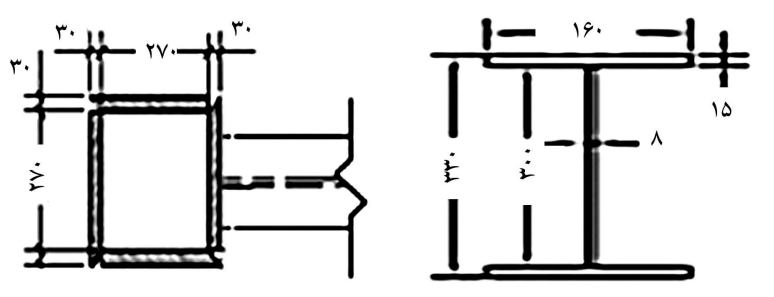

شكل r. ابعاد نمونهى كوحى آزمايشگاهى (ميلى متر).][']

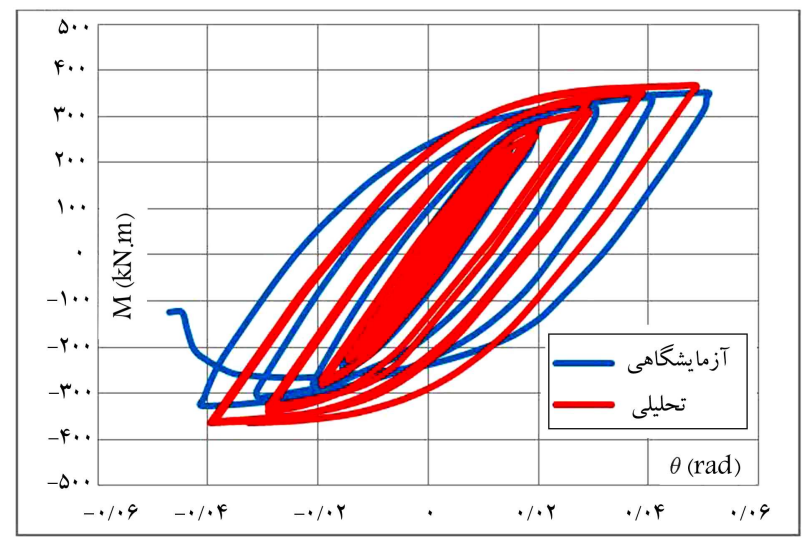

شكل لّ. نمودار لنكر - دوران (M-
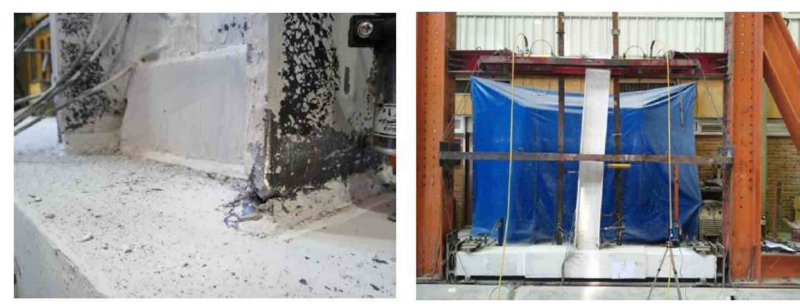

شكل \&. نمونهى اتصال كوحك در دوران هـ ه راديان.[1']

نمونه و مدلسازى از فولاد STrV استفاده و بار جرخهيى به انتهاى تير اعمال شده

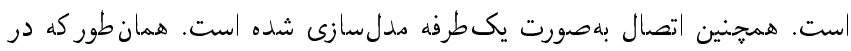

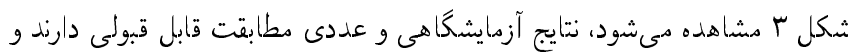

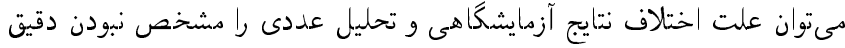

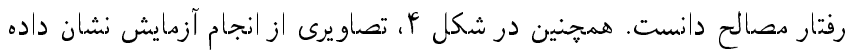
شده است. - است

با توجه به مشاهدههاى آزمايشگاهى نمونهى كوجى، در نيمسيكل رفت جرخهى

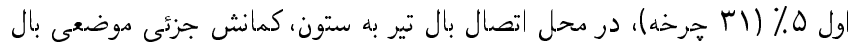

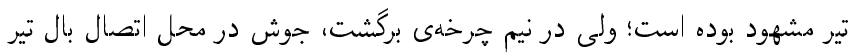

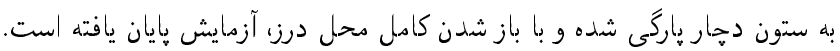

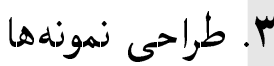

نمونهاى مورد دطالعه در نوشتار حاضر، از يك ساختمان آموزشى و در دست اجراى

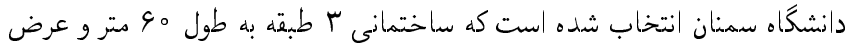

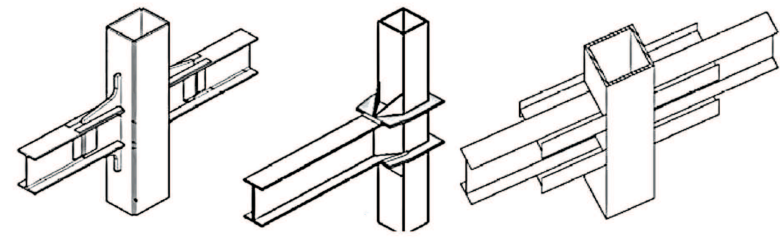

T)

الف) اتصال تير به ستون با سخت ب) سخت كننده هاى بيرونى حلقه يى؛

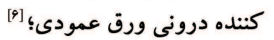

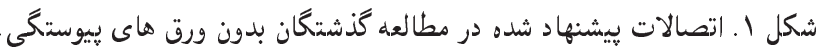

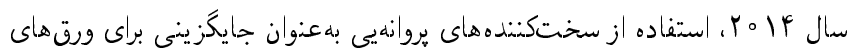

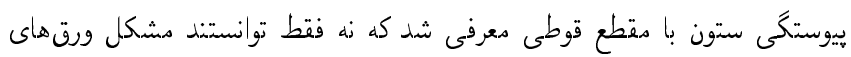

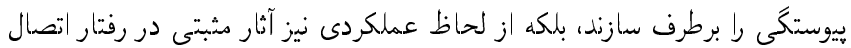

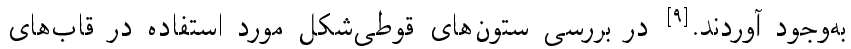

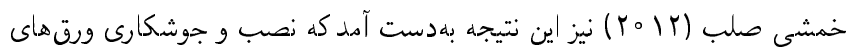

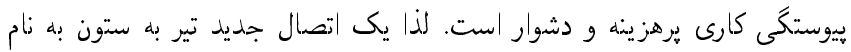

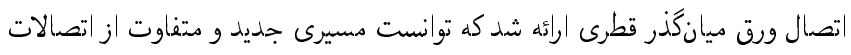

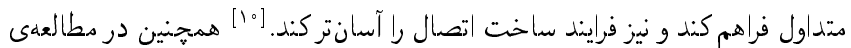

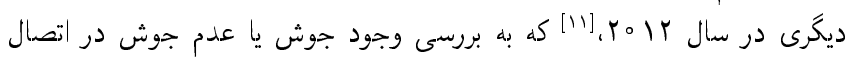

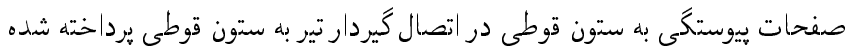

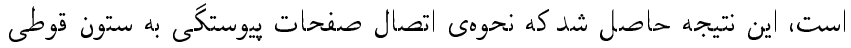

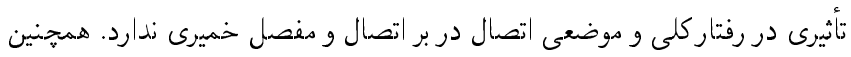

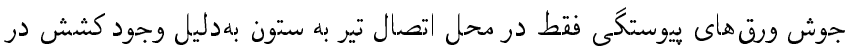

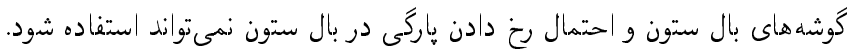

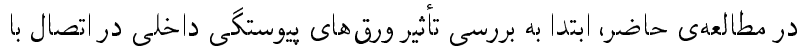

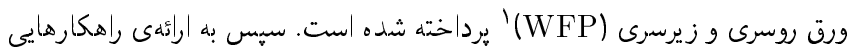

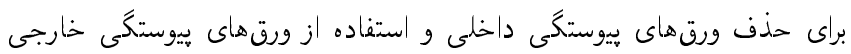

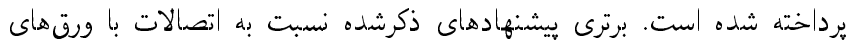

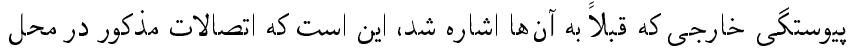

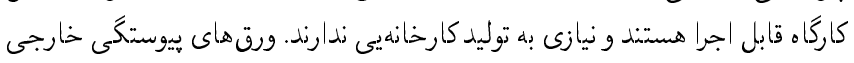

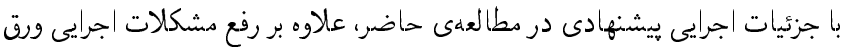

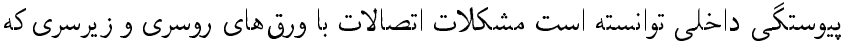
شاهل طول و ضخامت بالاى ورقهاى مذكور است، را مرتفع سازد.

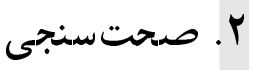

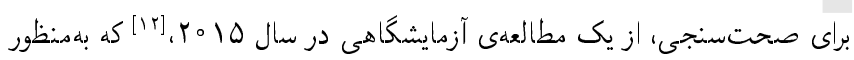

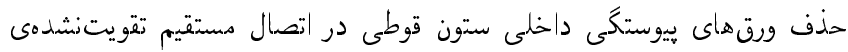

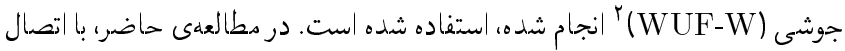
ورقهايى به ستون قوطى ضخاهت ناحيهى اتصال تير به ستون و و 4 سانتى متر

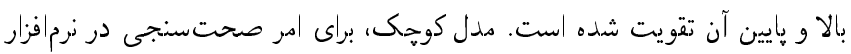

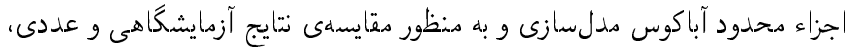

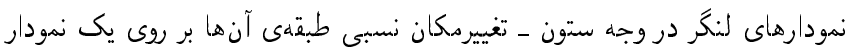

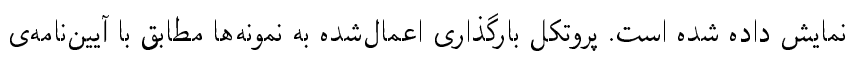

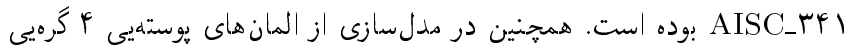

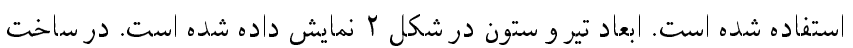




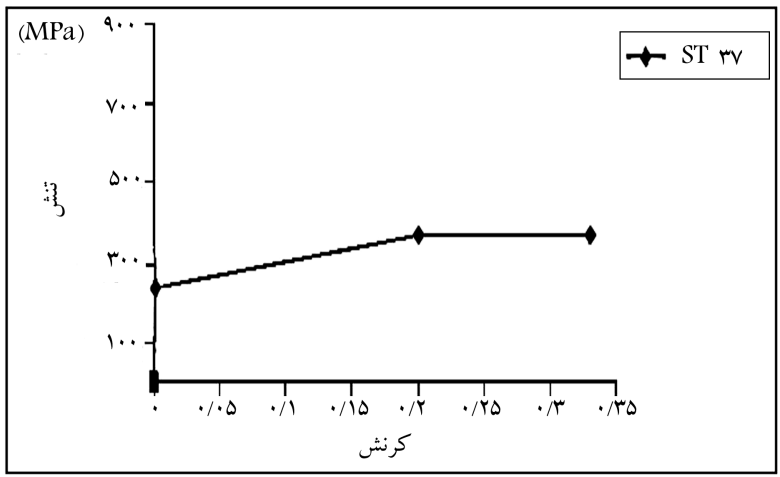

شكل צ. نمودار تنش كرنش فولادهاى STrV.

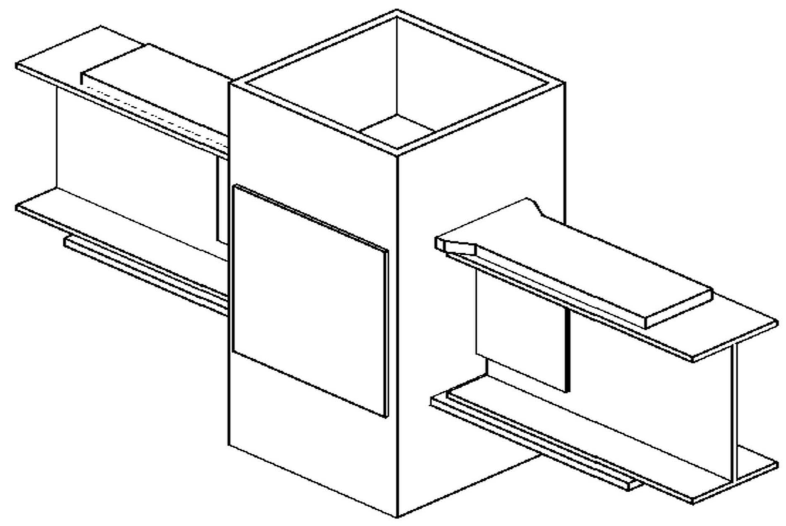

شكل V. اتصال با ورق روسرى و زيرسرى (WFP).

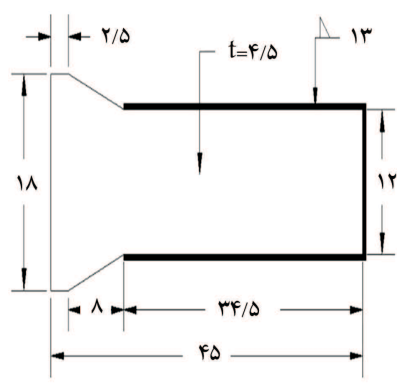

ب) ورق روسرى (ابعاد سانتى متر).

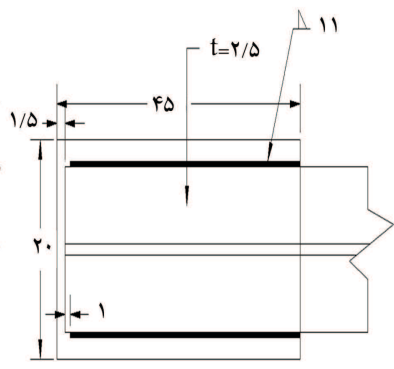

الف) ورق زيرسرى؛

شكل ^. جزئيات اتصال ورق هاى WFP.

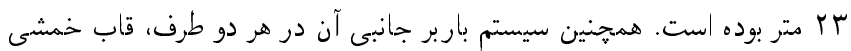

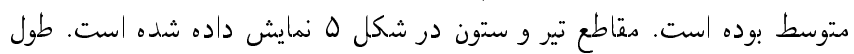

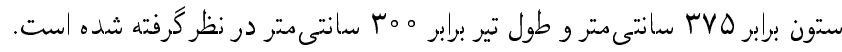

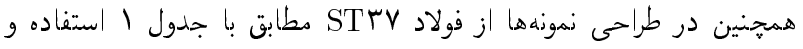

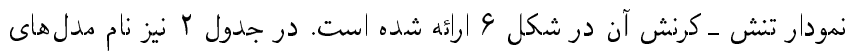
موردمطالعه ذكر شده است در شكلهاى ل و ^، جزئيات اتصال با ورق روسرى و زيرسرى (WFP) ارائه

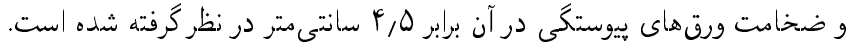
اتصال مذكور براساس آييناههى مبحث دهم مقررات ملى ساختمان، بخش اتصان اتصالات

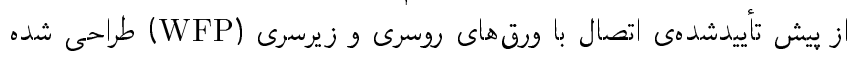
است.

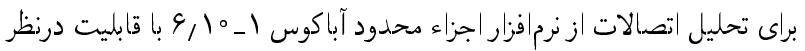

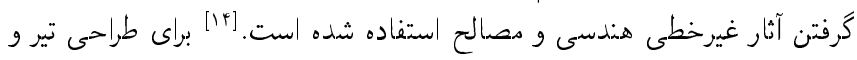

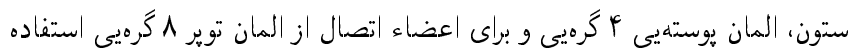
شده است.

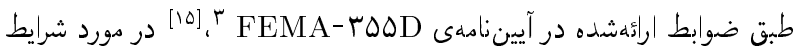

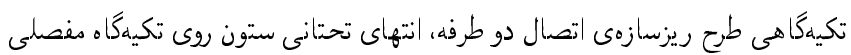

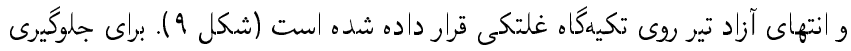

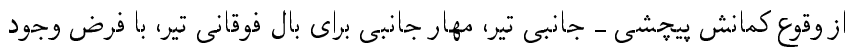

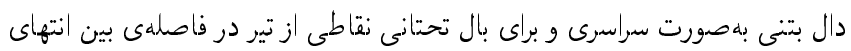
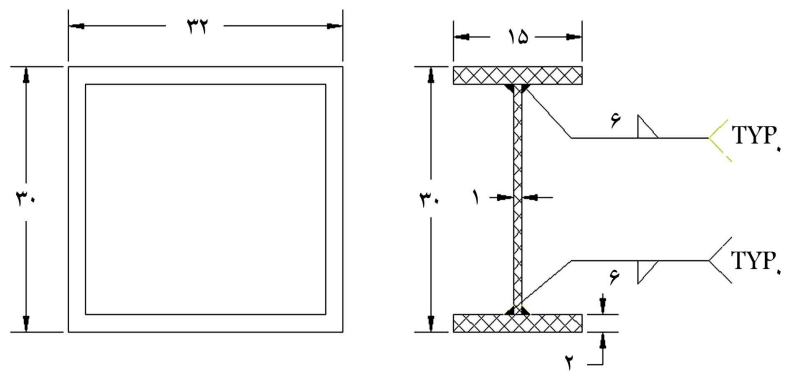

ستون

تير

شكل ه. مقاطع تير و ستون (ابعاد مقطع سانتى متر و ابعاد جوش بر حسب ميلى متر

جدول ا ـ مشخصات مكانيكى مصالح.

\begin{tabular}{|c|c|c|c|c|}
\hline$v$ & $\mathbf{E}(\mathrm{MPa})$ & Fu(MPa) & Fy(MPa) & نمونه \\
\hline $0, r$ & M10000 & rvo & TYO & STrV \\
\hline
\end{tabular}

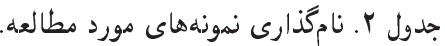

\begin{tabular}{|c|c|c|}
\hline 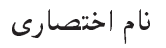 & توضيحات & مدل \\
\hline WFP-WP & اتصال با ورقهاى روسرى و زيرسرى همراه با ورقهاى بيوستكى داخلى & 1 \\
\hline WFP-WOP & اتصال با ورقهاى روسرى و زيرسرى همراه بدون ورقهاى ييوستكى & r \\
\hline WFP-UP & ورقهاى بيوستكى خارجى U شكل & r \\
\hline WFP-SW & ورقهاى ييوستگى خارجى همراه با جوش كام & r \\
\hline WFP-IP & نيمرخ I شكل & $\Delta$ \\
\hline
\end{tabular}




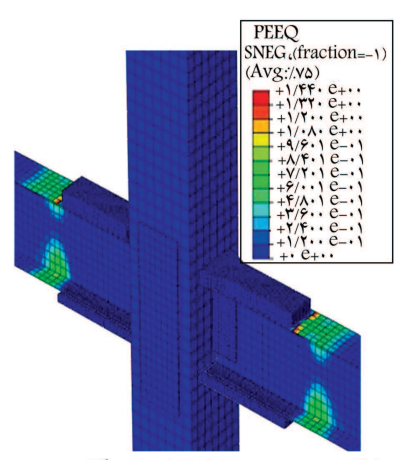

ب) كرنش خميرى معادل (تغيير مكان نسبى

طبقه \& ٪٪. راديان).

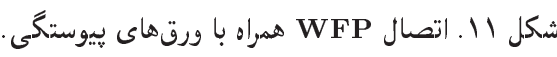

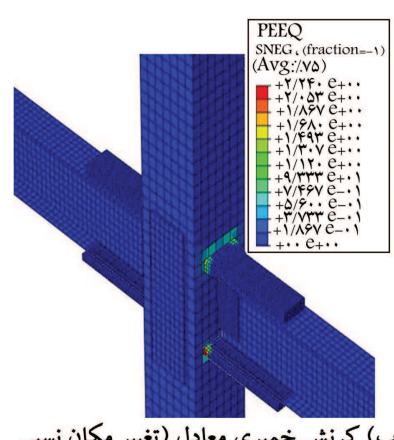

ب) كرنش خميرى معادل (تغيير مكان نسبى

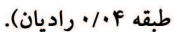

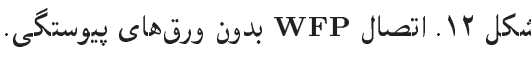
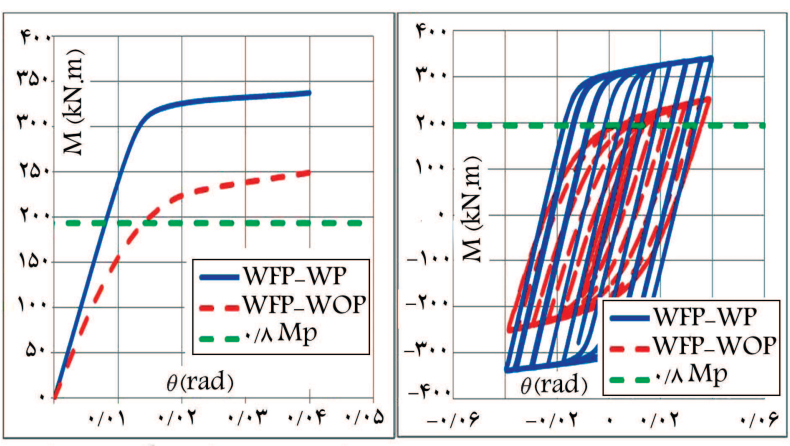

ب) نمودار يوش (تغيير مكان نسبى طبقه

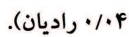

الف)نمودار جرخه يى لنكر -دوران (- (M- (M)؛

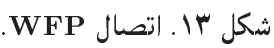

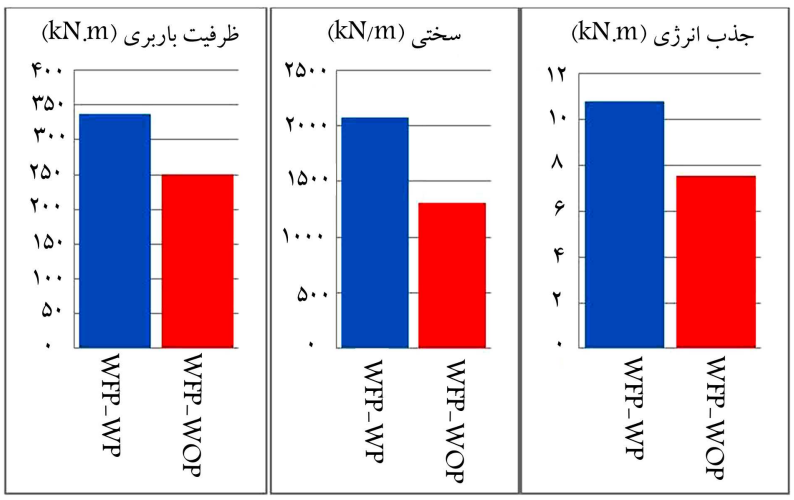

شكل ff ا. مقايسهى اتصالات از لحاظ سختى، جذب انرزى و ظرفيت بار برى.

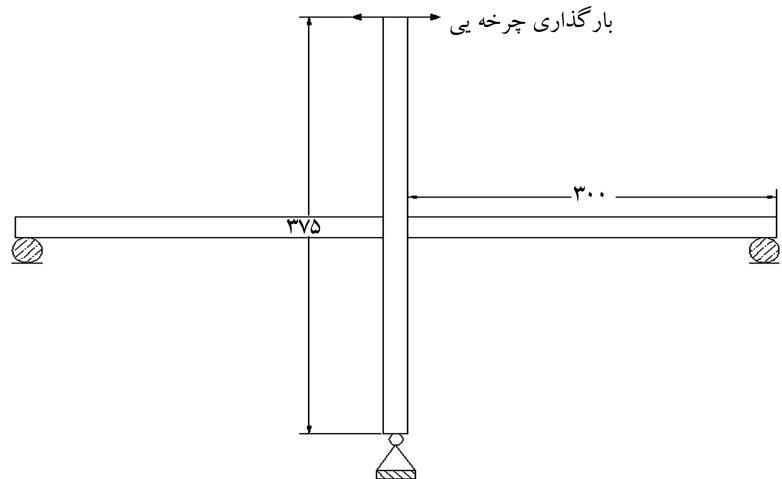

شكل 9 ش شرايط تكيهكاهى و ابعاد تير و ستون.

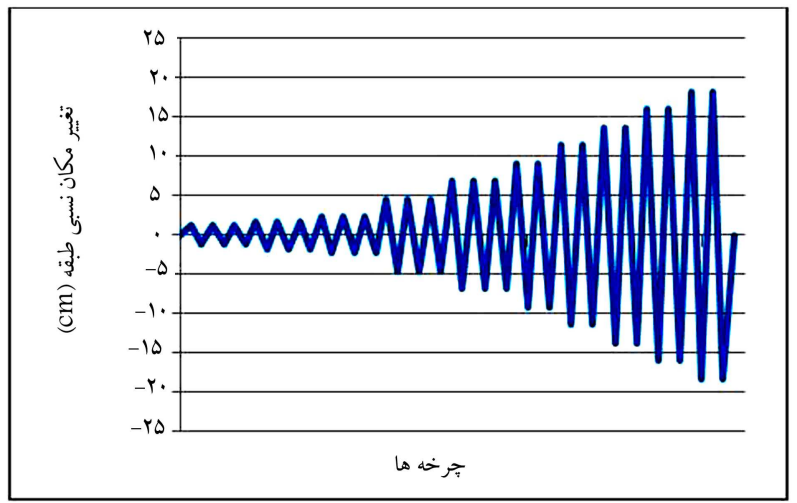

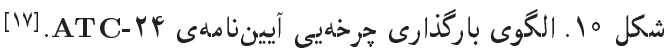

ناحيهى حفاظتشده تا نصف عمق تير بعد از آن و نقاطى در ابتداى تير دهار شده

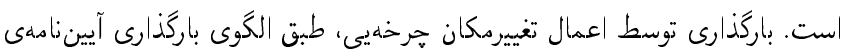
ATC-YF

شده است.

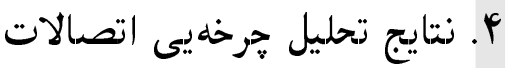

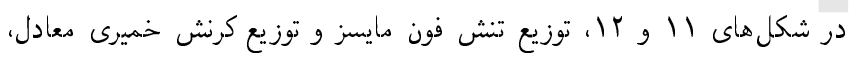

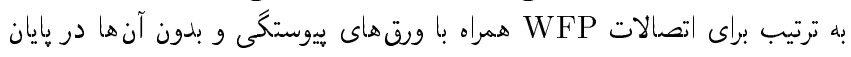

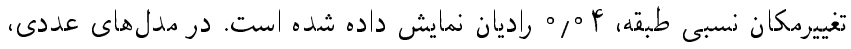

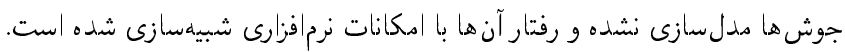

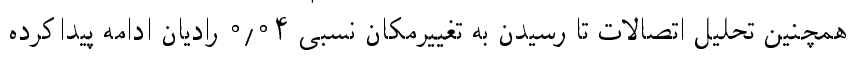

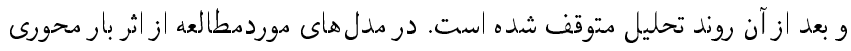
صرفنظر شده است. مطابق شكلهاى مذكور، در مدل با ورق بيوستگى، مفصل خميرى در فاصلهيى

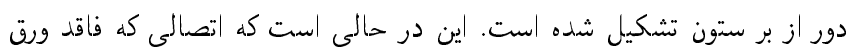

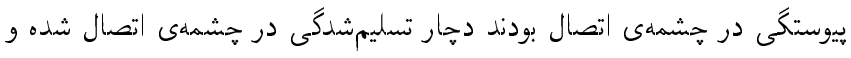

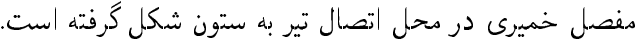

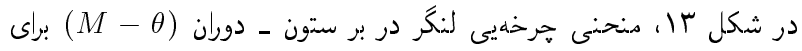

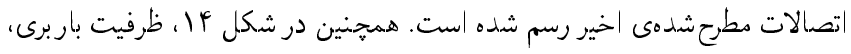

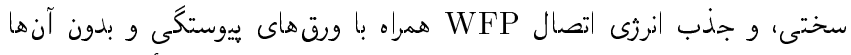

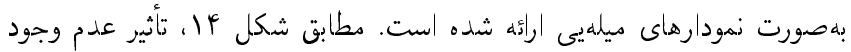




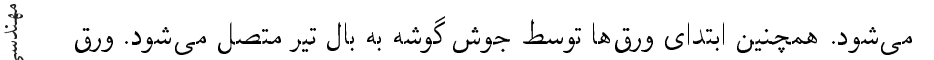

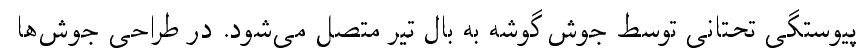

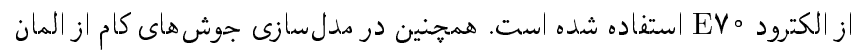

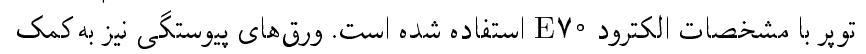

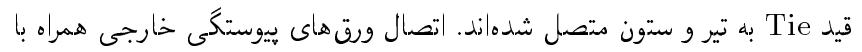

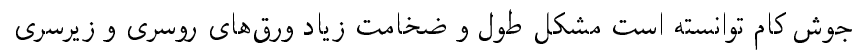

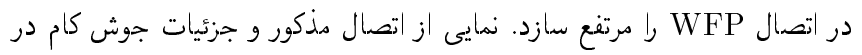
شكل 19 المشاهده مىشود.

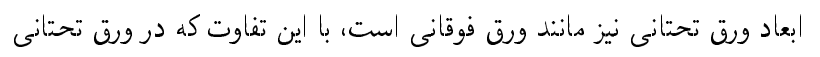

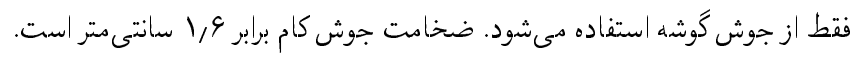

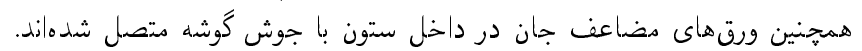

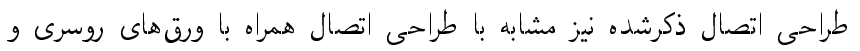
زيرسرى انجام شده است.

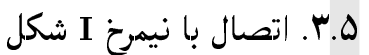

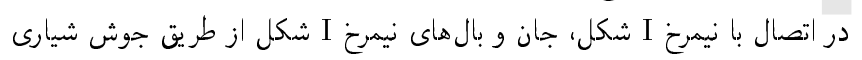

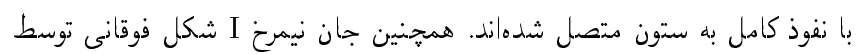

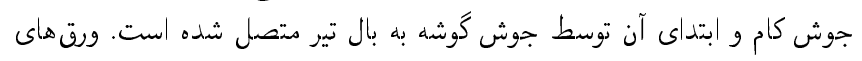

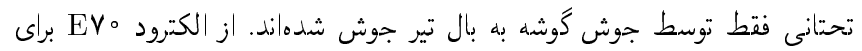

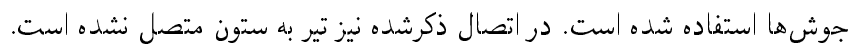

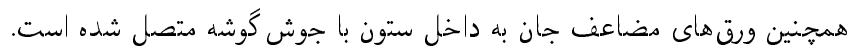

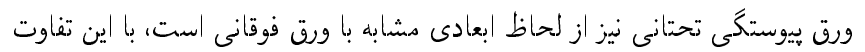

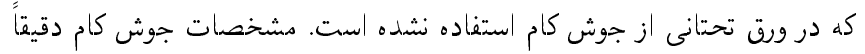

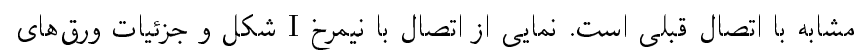
بيوستكى خارجى فوقانى در شكل VI لنمايش داده شده است.

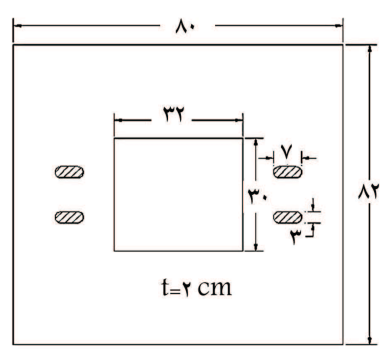

ب) ابعاد ورق فوقانى (ابعاد سانتى متر).

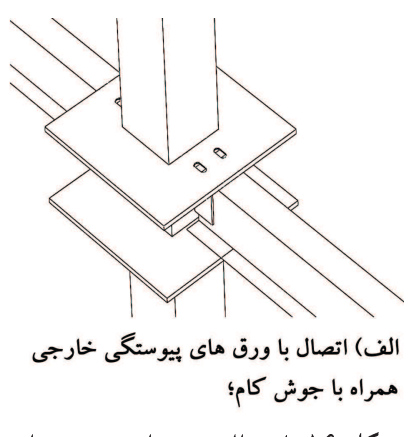

شكل 19. اتصال بيشنهادى ورق هاى بيوستكى خارجى همراه با جوش كام.

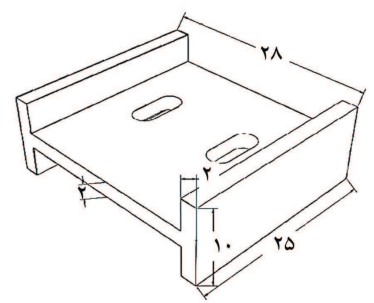

ب) ابعاد ورق فوفانى (ابعاد سانتى متر).

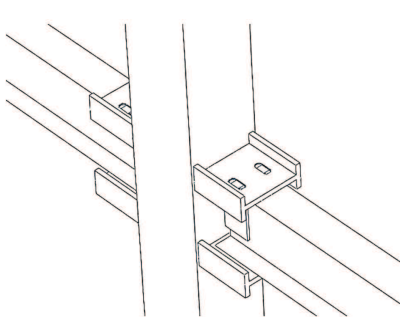

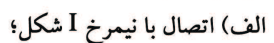

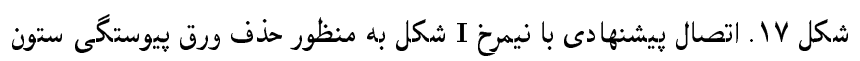
قوطى.
ورقهاى ييوستكى در جذب انزرى، سختى، و ظرفيت باربرى قابل توجه است و

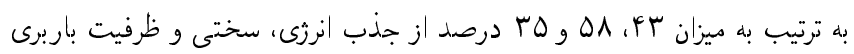
اتصال WFP كاهش يافته است.

\section{ه. يِشنهادهايى به منظور حذف ورقهاى بيوستكى} داخلى در بخش حاضر، سه بيشنهاد به منظور حذف ورقهاى يبوستگى داخلى ارائه شده

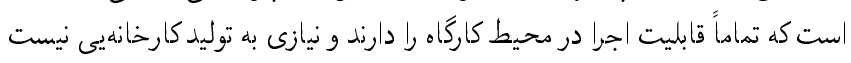

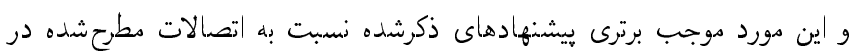

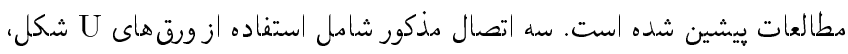

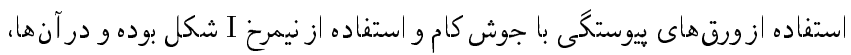

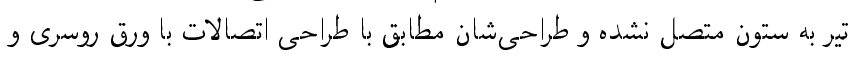

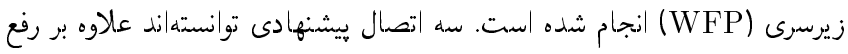

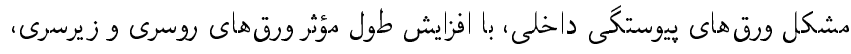

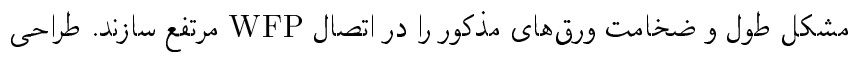

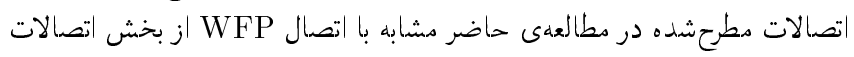

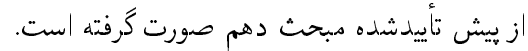

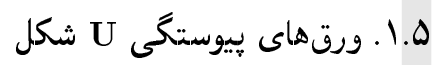

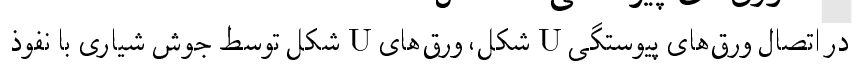

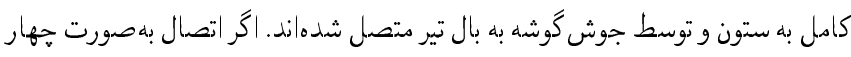

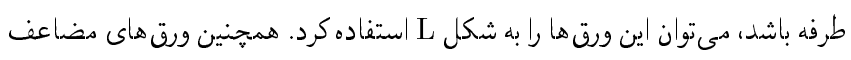

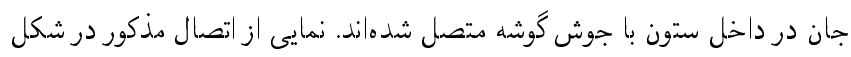

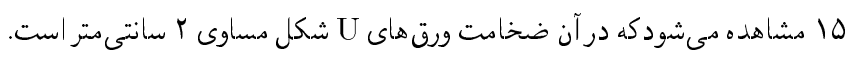

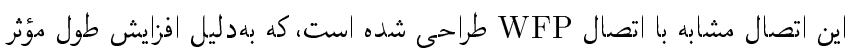

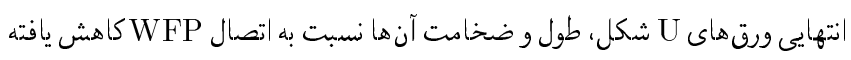

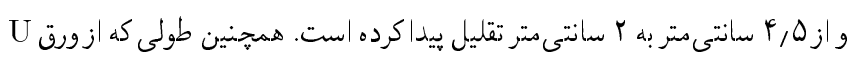

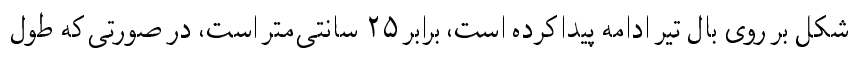

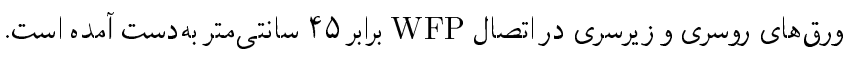

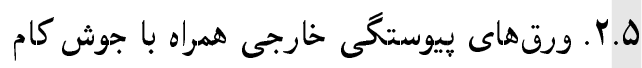

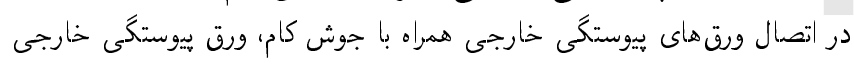
فوقانى توسط جوش شيارى با نفوذ كامل به ستون و توسط جال جوش كار كام به به تير متصل خارجى

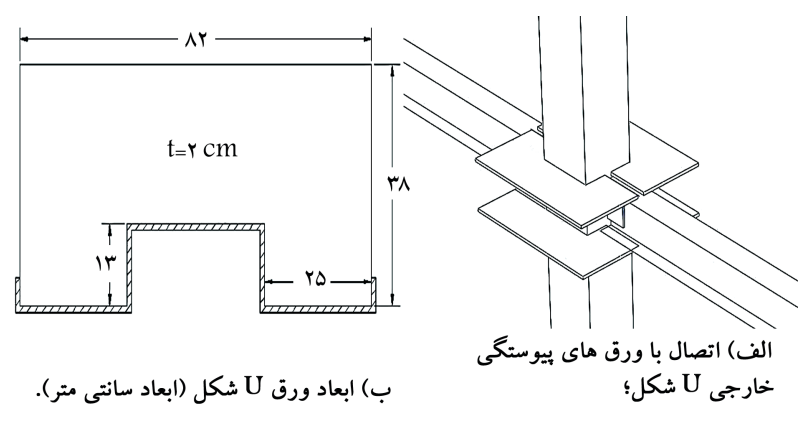

شكل ها ا. اتصال ييشنهادى همراه با ورق هاى يِيوستكى U شكل. 


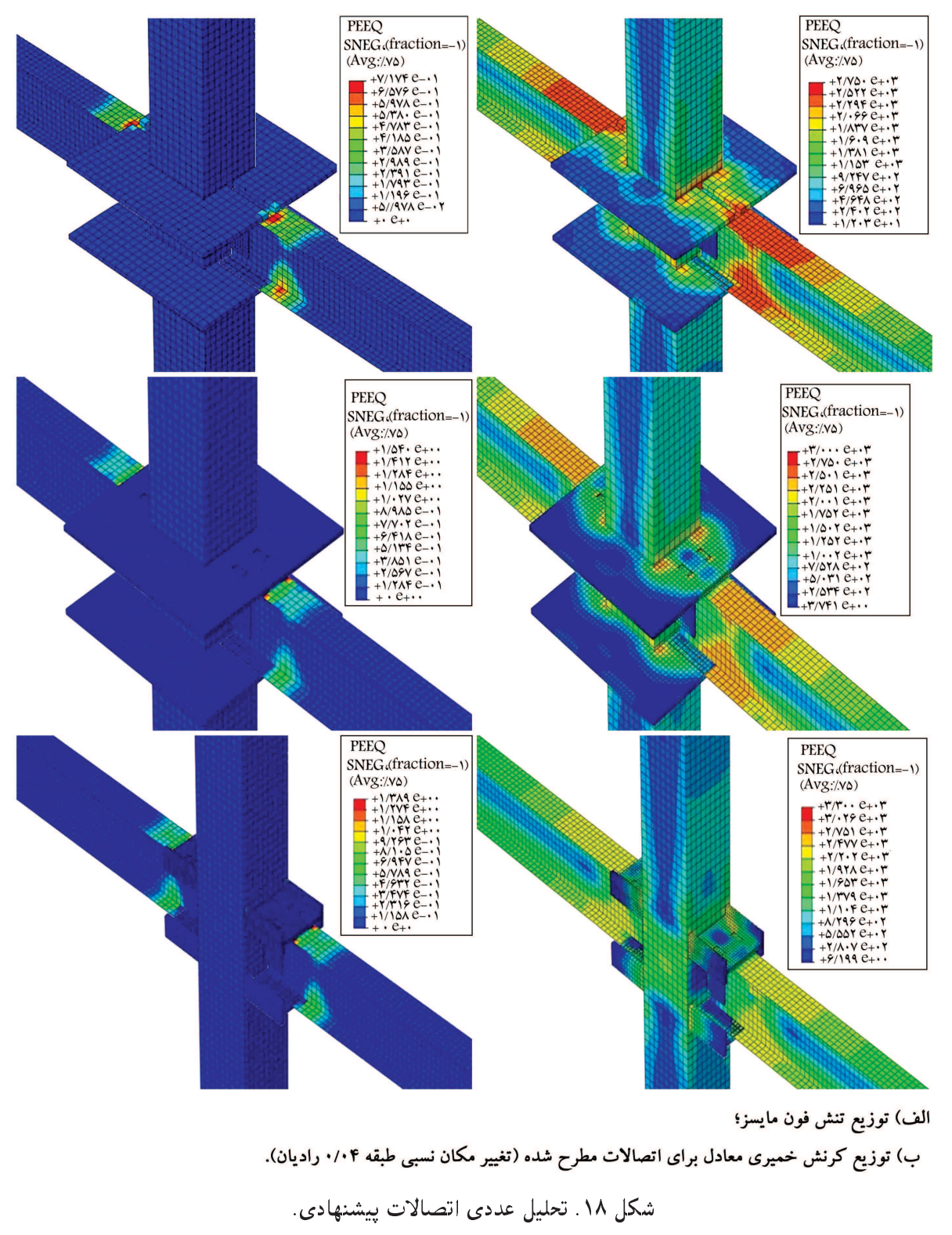

جدول r. مقايسهى اتصالات از لحاظ سختى، جذب انرزى و ظرفيت بار برى.

\begin{tabular}{|c|c|c|c|}
\hline ظرفيت & سختى & جذب & اتصال \\
\hline باربرى (درصد) & (درصد) & انزرى (درصد) & اتصال \\
\hline كاهش - q, 9 & كاهش - IV,0 & كاهش - 11,0 & WFP-UP \\
\hline كاهش - 1,9 & Sاهش - Q,V & كاهش - 1, & $\begin{array}{l}\text { WFP-PW } \\
\text { WFP-WP }\end{array}$ \\
\hline كاهش - 1, 1, & كاهش - 1,0 & كاهش - 1,0 & $\begin{array}{l}\text { WFP-IP } \\
\text { WFP-WP }\end{array}$ \\
\hline كاهش - 1,9 & كاهش - 11,9 & كاهش - & ميانكين \\
\hline
\end{tabular}

ه.† نتيجهگيرى و بحث بر روى نتايج

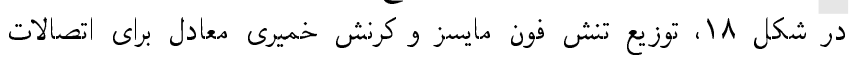
WFP-IP و WFP-SW ،WFP-UP

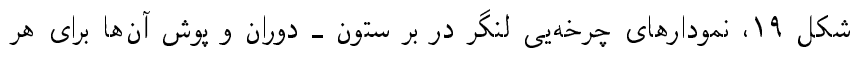

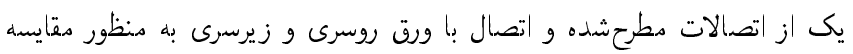

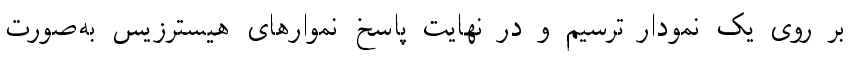

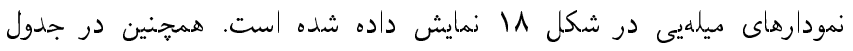

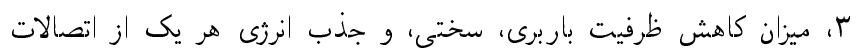

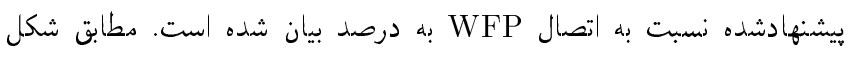

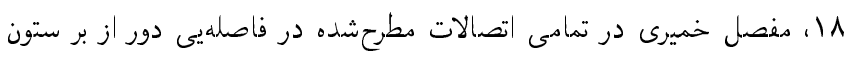

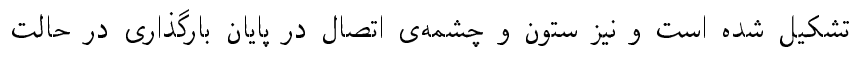

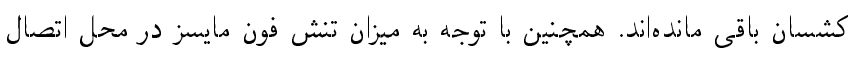

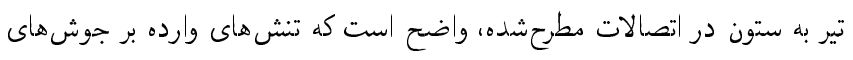



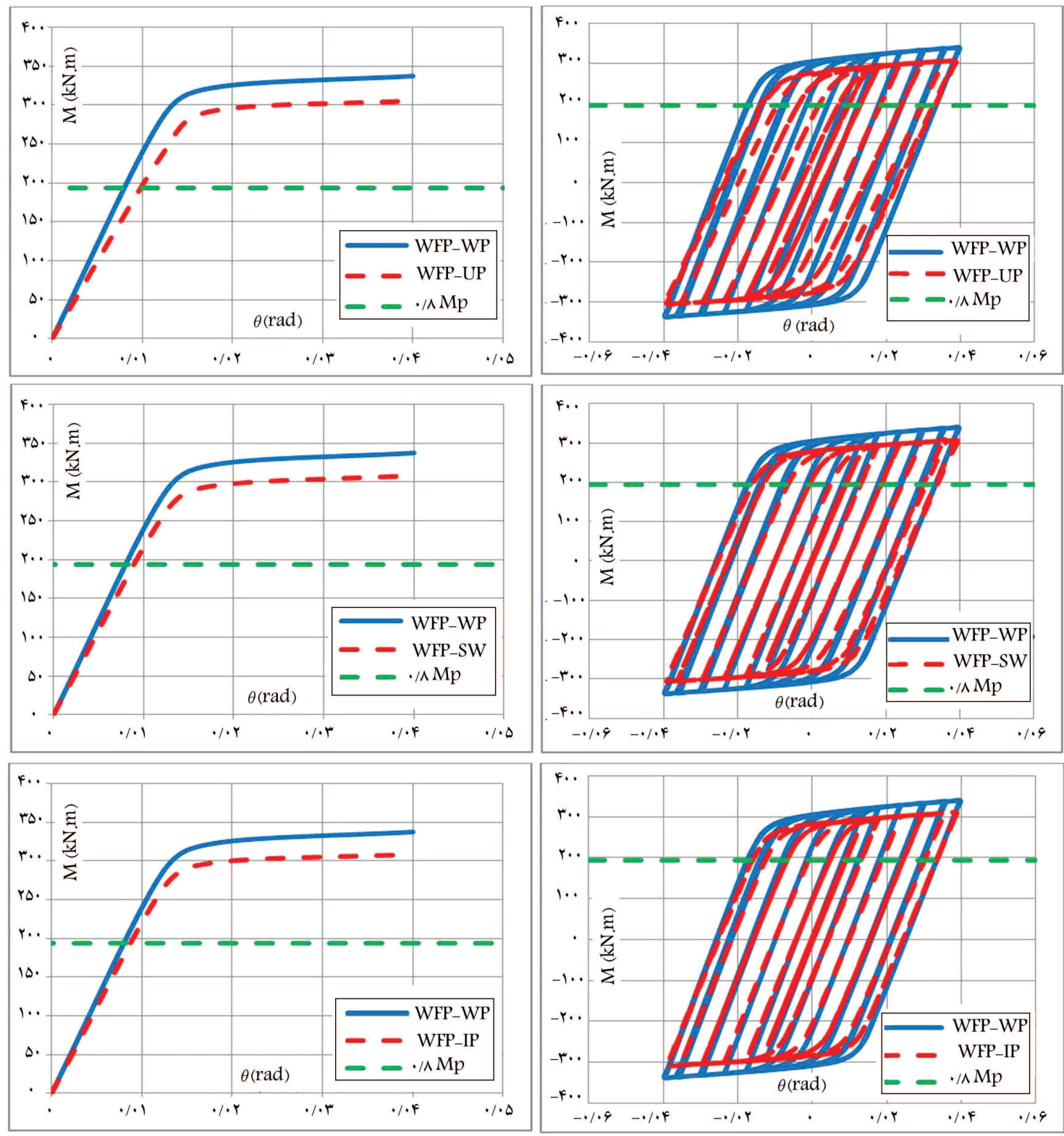

ب) نمودار يوش اتصالات (تغيير مكان نسبى \&٪/. راديان).

الف) نمودار جرخه يى لنخر - تغيير دوران ( (M-)؛

شكل 19. نتايج تحليل اتصالات بيشنهادى.

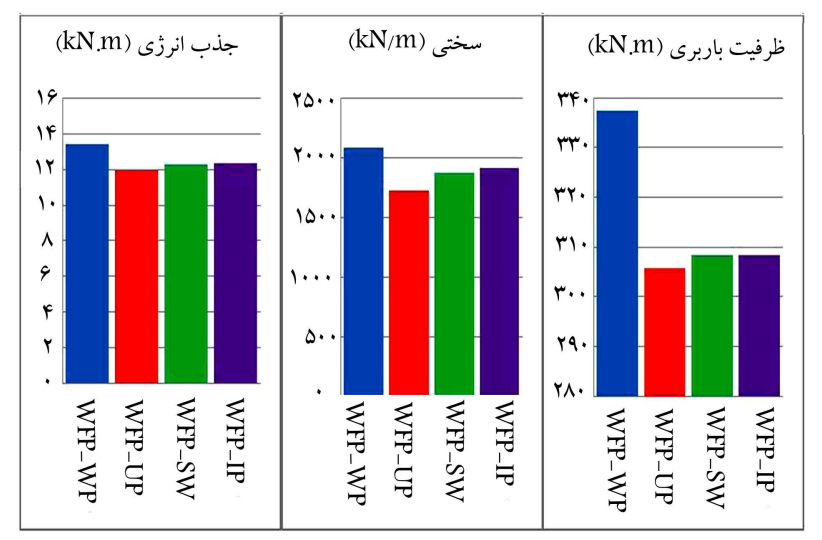

شكل ro. مقايسهى اتصالات از نظر جذب انرزى، ظرفيت بار برى و سختى.
محل اتصال از مقاومت آنها كمتر است و باركى در جوشها بهوجود نخواهد

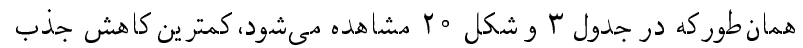

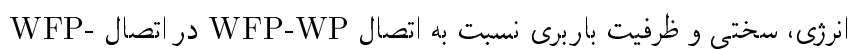

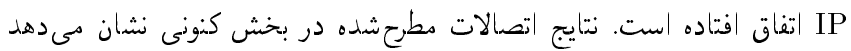
كه اتصالات يشينهادى با افت اندكى در ظرفيت باربرى، جذب انرئ انرزى، و سختى

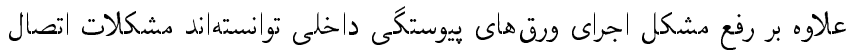

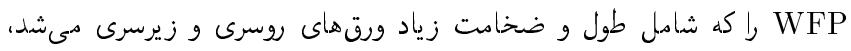

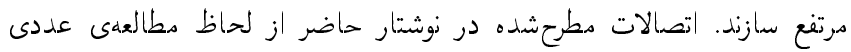

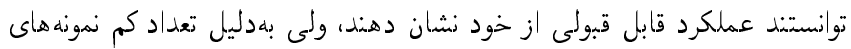

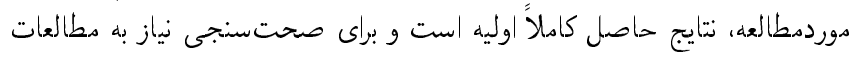




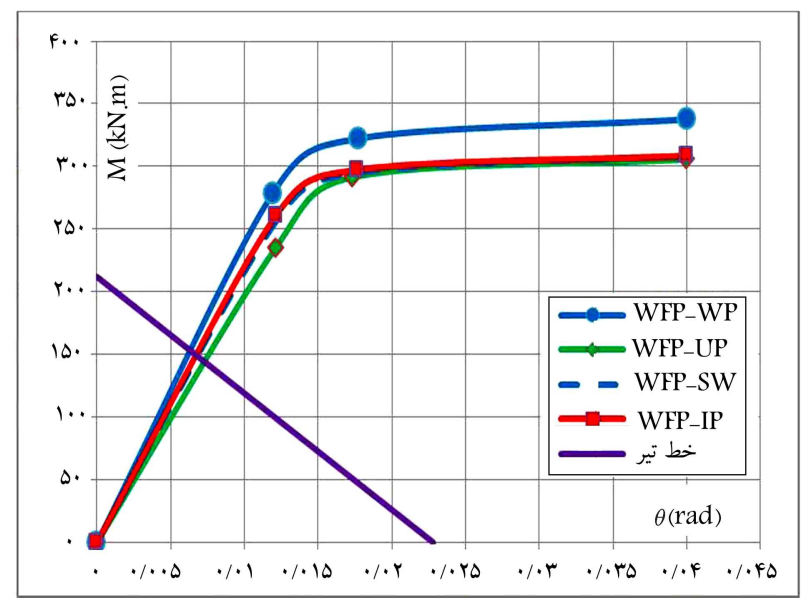

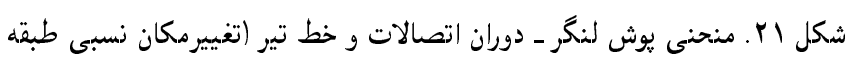

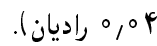

همانطور كه در جدول F مشاهده مى شود، بيشتر ين درصد كَيردارى مر بوط به

$$
\text { اتصال با نيمرخ I شكل بوده است. }
$$

\section{Vبقهبندى براساس معيار شكليذيرى}

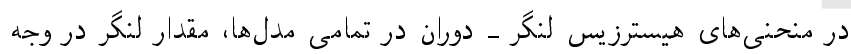

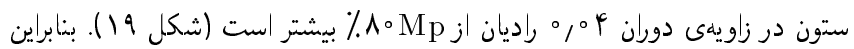

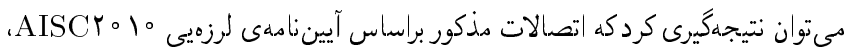

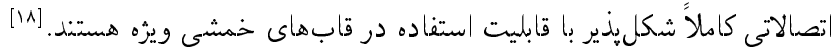

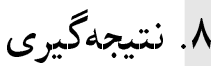

در نوشتار حاضر، ابتدا به بررسى تأثير ورقهاى بيوستخى در اتصال با ورق روسرى الئي

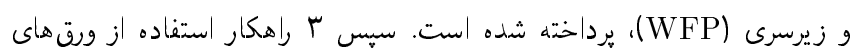

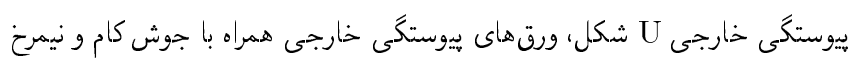

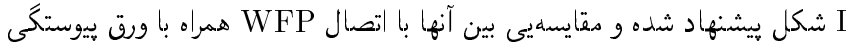

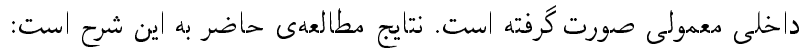
I. حذف ورقهاى بيوستكى در اتصالات WFP تأثير بهسزايى در ظرفيت باربرىى،

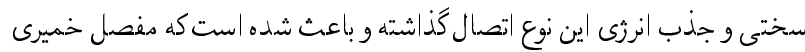

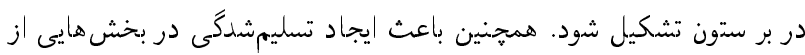

$$
\text { ستون شده است. }
$$

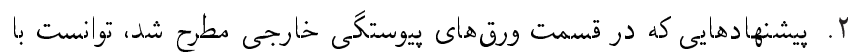

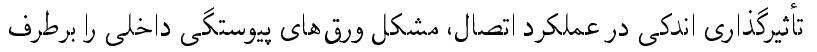

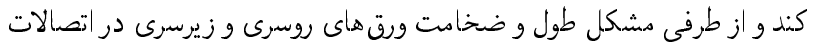
WFP را مرتفع سازد. r. در بيشنهادهاى ارائشده، نيمرخ I شكل عملكرد بهترى نسبت به دو دو اتصال ديكر از خود نشان داد. f. تمامى اتصالات مطرحشده، شكليذيرى قابل قبولى از خود نشان دادند و قابليت آنسان

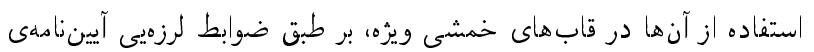

\begin{tabular}{|c|c|}
\hline درصد گيردارى & اتصال \\
\hline $81, r v$ & WFP-UP \\
\hline$v_{0}, r^{\prime}$ & WFP-SW \\
\hline$v 1, r \in$ & WFP-IP \\
\hline$v r, r o$ & WFP-WP \\
\hline
\end{tabular}

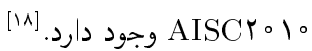

تكميلى مدلسازى و آزمايشكاهى خواهد بود. بايد توجه كرد كه نتايج بهدست آمده

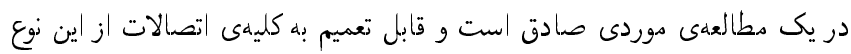

\section{4. درصد گيردارى اتصالات}

براى بهدستآوردن درصد گيردارى اتصالات از مفهوم خط تير التير استفاده مى آشود.

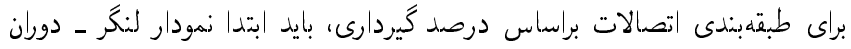

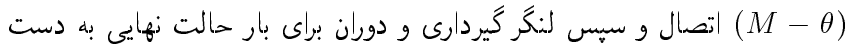

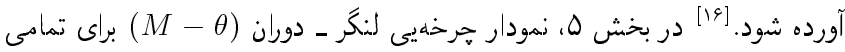

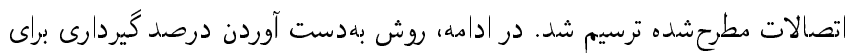
يك نمونه از اتصالات ارائه شده است.

1.4. محاسبهى درصد گيردارى اتصال WFP-UP (رابطهى ) ) $M_{f}=f_{y} \times S_{x}$

$$
=r r_{0} \circ \wedge \Lambda r=r \Pi 1 / 9 r k N . m
$$

مختصات نقطهى تلاقى محور افقى دستكاه مختصات لنكر - دوران با خط

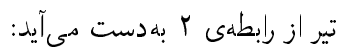

$$
\begin{aligned}
\theta_{a} & =\frac{M_{f} L}{r E I} \\
& =\frac{r l 19 r 00 \times 900}{r \times r / 1 \times 109 \times 1 r r F r, V}=0 / 4 r \Lambda r a d
\end{aligned}
$$

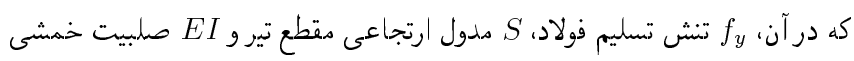
تير است و أM فضاى 1 - M، خط تير از نقاط با مختصات ( روابط ذكرشده، ميزان قابليت انتقال لنكر از راه اتصال به كمى كميت

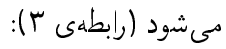

$$
\begin{aligned}
R & =\frac{M_{f} \backslash}{M_{f}} \times 100 \\
& =\frac{\mid F Y / 90}{r 11 / 9 r} \times 100=91 / r V
\end{aligned}
$$

درصد گيردارى ساير نمونهها با همين روش در جدول أ ارائه شده است. هميجنين

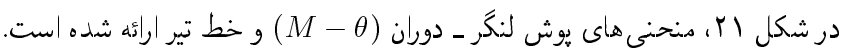


1. welded flange plate

2. welded unreinforced flange-welded web

3. federal emergency management agency

\section{منابع (References)}

1. Mokhtari, A., Mokari, J. and Tarverdilo, S. "Evaluation of beam to box column connections without continuity plates in panel zone", 6th International Conference on Earthquake Engineering, IIEES, Tehran, Iran (2011).

2. Mirghaderi, R. and Moradi, M. "Seismic behaviour of panel zones in beam to column connections with non-planner webs in moment resisting steel frames", 4th International Conference on Earthquake Engineering (2006).

3. Ting, L.C., Shanmugam, N.E. and Lee, S.L. "Boxcolumn to I-beam connections with external stiffeners", J. Construct Steel Res., 18(3), pp. 209-266 (1991).

4. Goswami, R. and Murty, C.V.R. "Improved configuration of I beam to box column connections in seismic steel moment frames", 14th Int Conf. on Earthquake Eng., Beiging, China (2008).

5. Goswami, R. and Murty, C.V.R. "Externally reinforced welded I-beam to box column seismic connection", $J$. Eng. Mechanics, 136(1), pp. 23-30 (2010).

6. Mirghaderi, S.R., Torabian, Sh. And Keshavarzi, F. "Ibeam to Box-column connection by a vertical plate passing through the column", J. Eng. Structures, 32(8), pp. 2034-2048 (2010).

7. Mokhtari, A., Mokari, J. and Kiyani, S. "Using external stiffeners instead of continuity plates in beam to box column connections", 9th International Congress of Civil Engineering, Isfahan University Technology, Isfahan, Iran (2010).

8. Saffari, H., Hedayat, A. and Soltani, N. "New alternatives for continuity plates in I-beam to box columns con- nections", Asian Jouranl of Civil Engineering, 16(2), pp. 219-233 (2015)

9. Ahmadi, M., Amiri, M. and Ahmadi, Mo. "Compare I beam to box column connections with external and internal continuity plates under cyclic loading", 2nd International Congress on Structure, Architecture \& Urban Development, Tabriz, Iran (2014).

10. Torabian, Sh., Mirghaderi, S.R. and Keshavarzi, F. "Moment connection between I beam \& built up square column by a diagonal through plate", Journal of Constructional Steel Res., 70, pp. 385-401 (2012).

11. Sabbaghi, MH. and Deylami, A. "Evaluation of existence or not existence continuity plates welding to box column in rigid connections", III National Steel \& Structures conf., Iran (2012).

12. Jahanbakhti, A. "Exploring the possibility of remove the continuity plates in I beam to box column connections", Structures Master Thesis, Faculty of Civil Engineering, K.N.Toosi University of Technology. Tehran, Iran (2015).

13. Code 10., Design and Construction Provisions For Structural Steel Buildings, Tehran, Iran (2012).

14. Hibbit, Karlsson, Sorenson, Inc. (HKS), "ABAQUS theory manual", Pawtucket, RI (2010).

15. FEMA-355D, "State of the art report on connection performance, SAC joint venture", Sacramento, California, Federal Emergency Management Agency (2000).

16. Nateghi, F. and Tabatabaei, Z. "The introduction of beam to box column rigid connections with side plates", J. Sharif Civil Engineering, 2(26), pp. 13-20 (2008).

17. ATC-24, "Guidelines for cyclic seismic testing of components of steel structures for buildings", Report No. ATC-24, Applied Technology Council, Redwood City, CA. (1992).

18. AISC, American Institude of Steel Construction, "Seismic provisions for structural steel buildings", Chicago, Illinois (2010). 